\title{
A vivid example of angioedema
}

\author{
Cemil Kavalci · Mehmet İnal · Alkin Colak • \\ Polat Durukan · Gülsüm Kavalci · Yunsur Çevik • \\ Sibel Güldiken
}

Received: 16 January 2009/ Accepted: 10 February 2009/Published online: 14 March 2009

(C) SIMI 2009

\section{Case report}

A 68-year-old hypertensive woman, who had been using $25 \mathrm{mg}$ of carvedilol daily for the past 5 years, woke up with edema of the tongue and dyspnea. At the admission to the rural hospital, $5 \mathrm{mg}$ of hydrocortisone and $5 \mathrm{mg}$ of dexchlorpheniramine were given intravenously, and the patient was sent to our department. It was learned from relatives of the patient that she had been given sublingual captopril in another hospital where she had been treated the day before for hypertension. Additionally, it was reported that the patient had also suffered from tongue edema in the prior year after using the same medication, sublingual captopril. On physical examination, she was alert, with vital signs: blood pressure 130/80 $\mathrm{mmHg}$, pulse rate 94 beats per minute, respiration rate 14 breathes per minute (Fig. 1). Inspiratory stridor was heard on auscultation, and the patient was not

This study was presented at 1st EACEM 5-9 November 2008, Antalya/Turkey.

C. Kavalci $(\bowtie) \cdot$ S. Güldiken

Emergency Department, Faculty of Medicine,

Trakya University, Güllapoglu, 22030 Edirne, Turkey

e-mail: cemkavalci@yahoo.com

M. İnal · A. Colak · G. Kavalci

Anesthesia Department, Faculty of Medicine,

Trakya University, 22100 Edirne, Turkey

P. Durukan

Emergency Department, Faculty of Medicine,

Erciyes University, Kayseri, Turkey

Y. Çevik

Emergency Department, Atatürk Training and Education Hospital, 06450 Bilkent, Ankara, Turkey

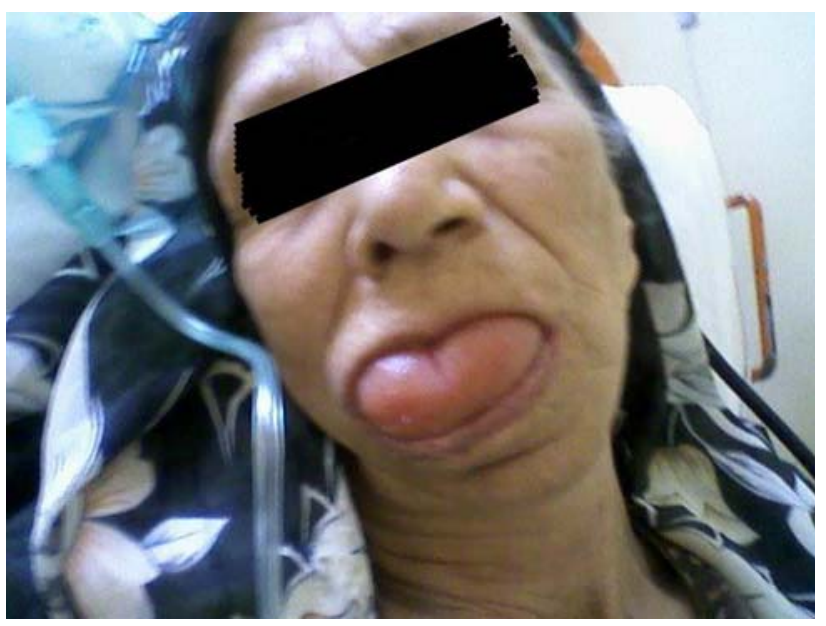

Fig. 1 Edema in the tongue

able to speak. She was breathing supplemental oxygen, placed on a cardiac monitor, and intravenous lines were established. Therapy was commenced with $0.3 \mathrm{mg}$ of a 1:10,000 epinephrine subcutaneously, $40 \mathrm{mg}$ methylprednisolone, $50 \mathrm{mg}$ diphenhydramine administered intravenously. Over the following $10 \mathrm{~min}$, subcutaneous $0.3 \mathrm{mg}$ of a 1:10,000 epinephrine was repeated a single time. The tongue of the patient decreased in size and she became able to speak. The patient stayed in the observation unit for $24 \mathrm{~h}$ and was discharged without any further problems.

\section{Discussion}

Angiotensin-converting enzyme (ACE) inhibitors are frequently used in the treatment of hypertension. Side effect profiles vary from minor allergic reactions to anaphylactic 
shock. It is common for patients using these drugs to develop a dry cough from this medication that may require cessation of the drug. An ACE inhibitor-induced angioedema is a relatively uncommon adverse drug reaction. Nevertheless, use of ACE inhibitor medication is a common trigger of angioedema occurring in $0.1-0.7 \%$ of patients. Fortunately, most cases are mild and transient. The edema usually presents in the head and neck, especially involving the face, lips, tongue, and glottis [1-3]. Epinephrine, antihistamines, and steroids are often used; however, their benefits have not been clearly demonstrated in the literature. Supportive treatment is mandatory [4].

\section{Conclusion}

Any patient, who will be treated, should be asked about a previous history of allergic reaction. Once even minor angioedema is attributed to an ACE inhibitor, an alternative class of antihypertensive medication should be chosen.
Individuals with a probable history of idiopathic angioedema should not be given ACE inhibitors.

Conflict of interest statement The authors declare that they have no conflict of interest related to the publication of this manuscript.

\section{References}

1. Carr BHRS (2004) Anaphylaxis and acute allergic reactions. In: Tintinalli JE, Kelen GD, Stapczynski (eds) Emergency medicine. A comprehensive study guide, 6th edn. McGraw-Hill, NewYork, pp 247-252

2. Yanturali S, Ergun N, Eminoglu O et al (2004) Life threatening tongue angioedema associated with an angiotensin-converting enzyme inhibitor. Vet Hum Toxicol 46:85-86

3. Arzi H, Ben-Dror G, Mijiritzky Y (2002) Angioedema of the tongue and oropharynx after treatment with sublingual captopril. Harefuah 141:869-870

4. Grant NN, Deeb ZE, Chia SH (2007) Clinical experience with angiotensin-converting enzyme inhibitor-induced angioedema. Otolaryngol Head Neck Surg 137:931-935 